\title{
Covid 19 Disease - A Case Series of Cases Reported with Different Treatment Approaches
}

\author{
Dr.Yaser Arafath*, Dr.Sooraj Rajagopal ${ }^{1}$, Tasneem Abdul Gafoor ${ }^{2}$, Ajeena Anto², Dr.S.Haja Sherief ${ }^{3}$ \\ ${ }^{*}$ Consultant and Family Physician, IQRAA International Hospital and Research Centre, Calicut, India. \\ ${ }^{1}$ Associate Professor, Department of Physical medicine and Rehabilitation, Calicut, India. \\ 2Pharm.D Interns, Department of Pharmacy Practice, Nandha college of Pharmacy, Erode, Tamil Nadu, India. \\ ${ }^{3}$ Department of Pharmacy Practice, Nandha College of Pharmacy, Erode, TamilNadu, India. \\ *Corresponding author's E-mail: tasneem95m2@gmail.com
}

Received: 22-08-2020; Revised: 21-10-2020; Accepted: 28-10-2020; Published on: 15-11-2020.

\section{ABSTRACT}

The novel corona virus (COVID-19) also known as severe acute respiratory syndrome. Corona virus 2 (SARS-CoV-2) has become a global pandemic and a major disease affecting our healthcare systems. It is an envelope, positive-sense RNA virus belonging to the family of beta-coronaviridae. This virus is well known for developing severe bilateral pneumonia and acute respiratory distress syndrome (ARDS) which can result in breathing difficulty requiring mechanical ventilation and intensive care unit management. COVID-19 was first identified in December 2019 in Wuhan city, China, and later spread to many other regions in China. Presently, more than 212 countries and territories have confirmed cases of covid 19 infection. Although several companies have already begun trials for covid 19 vaccines, healthcare teams have been using a wide-range of drugs to treat the viral symptoms; there is still no approved treatment regimen for COVID-19 infections. The alarming increase in cases per day adds an extra pressure to find a cure and to reduce the global health burden and mortality rate. This case series will discuss 5 different cases of covid 19 infections with different pharmacotherapy and patient outcomes.

Keywords: Novel corona virus, COVID-19, acute respiratory syndrome.

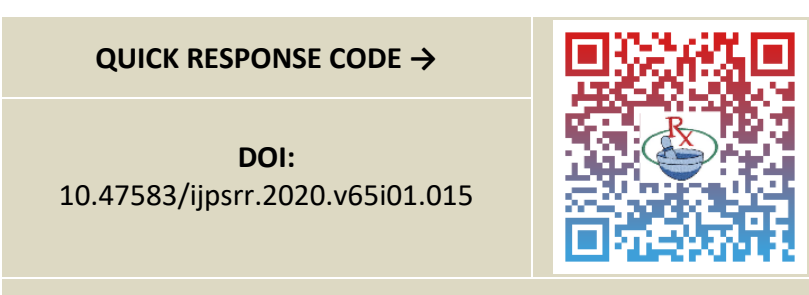

DOI link: $\underline{\text { http://dx.doi.org/10.47583/ijpsrr.2020.v65i01.015 }}$

\section{INTRODUCTION}

S evere acute respiratory syndrome corona virus 2 (SARS-CoV-2), which causes corona virus disease (COVID-19) has been found to be the cause of severe pneumonia and acute respiratory distress syndrome (ARDS) with a significant high mortality rate. ${ }^{1}$ The infection was first diagnosed and reported in December 2019 in Wuhan city, China, and later spread to many other areas in China. As of 14 September 2020, the World Health Organization (WHO) had documented $28,918,900$ positive COVID-19 cases, and the death toll attributed to COVID-19 had reached 922252 worldwide. ${ }^{2}$ So far, more than 212 countries and territories have confirmed cases of SARSCoV2 infection. COVID-19 has become the main focus of the medical world and the pandemic of $2020 .{ }^{1}$

On $30^{\text {th }}$ January 2020, the WHO declared COVID-19 as a Public Health Emergency of International Concern. ${ }^{3}$ The first SARS-CoV-2 positive case in India was reported in the Kerala state on January 30th, 2020. The recent epidemic of COVID-19 in several countries is analogous to the previous outbursts of SARS and Middle East respiratory syndrome (MERS) that reported in 2003 and 2012 in China and Saudi Arabia, respectively. ${ }^{4}$

Coronavirus is accountable for both SARS and COVID-19 diseases; they mainly affect the respiratory tract and cause major disease outbreaks worldwide. SARS is caused by SARS-CoV, whereas SARS-CoV2 causes COVID-19. So far, there is no particular treatment available to manage SARS or COVID-19. SARS-CoV-2 is easier to transmit than SARSCoV. The two possible reasons could be (i) the viral load (quantity of virus) tends to be relatively higher in COVID19-positive patients, and (ii) the binding affinity of SARSCoV-2 to host cell receptors is higher than that of SARS-CoV $(13,14) .{ }^{4}$

Clinical Picture of COVID-19 ranges from asymptomatic to severe illness and death. Common symptoms include fever/chills, cough, and breathlessness, fatigue, muscle or body pain, headache and new loss of smell or taste. ${ }^{5}$ Symptoms may develop 2 days to 2 weeks following viral exposure. ${ }^{5}$ A pooled analysis of 181 confirmed cases of COVID-19 outside Wuhan, China, found the mean incubation period to be 5.1 days and that $97.5 \%$ of individuals developed symptoms within 11.5 days of infection. ${ }^{6}$

The most common serious presentation of COVID-19 is pneumonia. Fever, cough, dyspnea, and abnormalities on chest imaging are common in these cases. ${ }^{7-10}$ Huang et al found that, among patients with pneumonia, $99 \%$ had fever, $70 \%$ reported fatigue, $59 \%$ had dry cough, $40 \%$ had anorexia, 35\% experienced myalgias, 31\% had dyspnea, and $27 \%$ had sputum production. ${ }^{10}$ 
The virus that causes COVID-19 is mainly transmitted through droplets of an infected person by coughing, sneezing, or exhalation. These droplets are easily spread by breathing in the virus within close proximity of someone who has COVID-19, or by touching eyes, nose or mouth after touching a contaminated surface. ${ }^{2}$

The diagnostic tool is mainly through clinical presentation and with tests such as Nucleic acid amplification testing (NAAT), Antigen (Ag), Antibody (Ab) detection .The CDC has developed a diagnostic test for virus detection and received special Emergency Use Authorization (EUA) from the FDA on February 4, 2020, for its use. ${ }^{11}$ The test is a realtime reverse transcription-polymerase chain reaction ( $r$ RT-PCR) assay that can be used to diagnose the virus in respiratory and serum samples from specimens. ${ }^{12]}$ On April 13, 2020, the FDA granted EUA for a saliva-based COVID-19 test, which can be used to test patients' selfcollected saliva rather than swabs collected by healthcare personnel that helps in potentially limiting exposure and increasing the volume for testing. ${ }^{13}$

Cheng et al advised that antibody testing could also be ready to aid specific diagnostic scenarios but should not be used for diagnosing acute COVID-19. ${ }^{14}$

Laboratory findings in covid 19 patients includes Leukopenia, leukocytosis, and lymphopenia were common among early cases. ${ }^{15,10}$ Lactate dehydrogenase and ferritin levels are commonly elevated but not in all cases. ${ }^{10} \mathrm{Wu}$ et al reported that, among 200 patients with COVID-19 who were hospitalized, older age, neutrophilia, and increased lactate dehydrogenase and D-dimer levels raises the risks of ARDS and death. Since the disease presents itself as pneumonia, radiological imaging has a crucial role in the diagnosis, management, and follow-up. Chest computed tomography (CT), in particular highresolution CT (HRCT), is another method of choice in the study of COVID-19 pneumonia, even in the initial stages.

There are presently no medications or other treatment regimens approved by the U.S. Food and Drug Administration (FDA) to treat and prevent COVID-19. Current clinical management includes infection prevention and control measures and supportive therapy, including supplemental oxygen and mechanical ventilatory support when required. In a patient with a SpO2 < 93-94\% (<88$90 \%$ if COPD) or a respiratory rate $>28-30 / \mathrm{min}$, or dyspnoea, oxygen must be administered by a $40 \%$ Venturi mask. N1 Continuous positive airway pressure CPAP has a central role in managing COVID-19-associated respiratory failure. Although no antiviral treatments have been approved, several viewpoints have been put forward such as using LOPINAVIR/RITONAVIR (400/100 mg orally every 12 hours). Several anti-flu drugs such as OSELTAMIVIR have also been used for the treating COVID-19 patients. ${ }^{16}$ Another anti-flu medication; FAVIPIRAVIR demonstrated a certain efficacy against SARS-CoV-2 in vitro. In severe Covid 19 induced ARDS, steroids like DEXAMETHASONE, METHYLPREDNISOLONE are usually used (e.g., METHYLPREDNISOLONE $1 \mathrm{mg} / \mathrm{kg} /$ day).
Antimalarials such as CHLOROQUINE (500 mg every 12 hours) and HYDROXYCHLOROQUINE (200 mg every 12 hours) were proposed as immunomodulatory therapy and are now proving its efficacy. Antibodies taken from the blood of healed individuals represent a therapeutic option currently is under study. Another drug under study is ACALABRUTINIB, a selective Bruton tyrosine kinase inhibitor, which regulates macrophage signaling and activation. Studies proved that treatment improved need for oxygenation in a majority of patients, ameliorating measures of inflammation such as C-reactive protein and IL-6. ${ }^{17}$

\section{CASE PRESENTATION}

\section{Case Report 1}

A case of 36-year-old female patient came with the complaints of decreased appetite, tiredness for past 1 week. She had a history of fever and vomiting for past 2 days and 2 episode of seizure for 1 day. The patient was a known case of systemic lupus erythematosus, panhypothyroidism, and autoimmune polyglandular syndrome dysfunction, Otomycosis of right ear, SIADH, seizure and depression and was on regular treatment for past 4 years. Patient has no travel history and unknown exposure history. The patient was screened for Truenaat covid-19 and became positive. Based on the signs and symptoms, she was categorized as Category B.

On examination, patient was febrile- $98^{\circ} \mathrm{F}$, BP110/80mmHg, HR-90bpm and Spo2-98\%. Investigations showed HB-9.6g/dl, WBC-3,600 cells/cumm, ESR: $10 \mathrm{~mm} / \mathrm{hr}, \mathrm{PLT}-1.5$ lakhs/cumm, D-dimer-340.33ng/ml and CRP-3.26mg/ml. The patient had low levels of sodium accounted for $125 \mathrm{mmol} / \mathrm{L}$ and was immune thrombocytopenic. The patient was treated with T.SODIUM VALPROATE+VALPROIC ACID 500mg BD, T.CLOBAZAM 5MG BD,T.LEVOTHYROXINE 25mcg OD, T.CALCIUM CARBONATE 500mg HS,T.SERTRALINE 100mg $1 / 2$ OD, T.CLONAZEPAM 0.2mg HS, INJ.PIPERACILLIN TAZOBACTAM 4.5gm IV Q8H, CANDID EAR DROPS 3DROPS TDS RIGHT EAR, INJ.PAN 4OMG OD. For Covid 19 infection, patient was managed with T.HYDROXYCHLOROQUINE 200mg BD and T.FAVIPIRAVIR 1800MG BD as loading dose for 1 day followed by maintenance dose $800 \mathrm{mg}$ for 5 days. The patient was on T.PREDNISOLONE 10mg BD for SLE was changed to INJ.HYDROCORTISONE $100 \mathrm{mg}$ IV TID. On $5^{\text {th }}$ day, patient developed bradycardia (hr-44bpm) and breathlessness and was managed by INJ.HYDROCORTISONE 50mg STAT with T.DERIPHYLINE 150mg BD and T.ORCIPRENALINE 10mg TDS.

Following 14 days course in hospital, the patient was symptomatically improved and had favourable outcome. The sodium and platelet level were also corrected. The patient was tested for rapid antigen test and was found to be negative. Hence, she was discharged without any complications. 


\section{Case Report 2}

A case of 36 year old female patient came with the complaints of headache and cough for past 2 days and 1 episode of seizure. She was a known case of old CVA with right sided hemiparesis and on regular treatment for past 5 years. Patient was screened for Truenaat covid-19 and became positive. She had no travel history and had an unknown exposure. Based on the signs and symptoms, she was categorized as Category B. On examination, patient was afebrile, BP-135/85mmHg, PR-90bpm and SPO2-96\%. The investigation showed $\mathrm{Hb}: 13.8 \mathrm{~g} / \mathrm{dl}$, Plt: 2.6lakhs/cumm, D-Dimer:382.06 ng/ml. The patient was managed seizure with T.LEVETIRACETAM 500MG BD and CVA with T.ASPIRIN $150 \mathrm{mg}$ OD, T.ATORVASTATIN $40 \mathrm{mg}$ HS. T.VITAMIN C 500 mg BD, T.CALDAY (CALCIUM+MAGNESIUM+ZINC+VITAMIN D3), T.ZINC 50 mg OD, T.AZITHROMYCIN 500 mg OD, for 5 days was given for covid infection. On the fifth day of admission, the patient developed cough, cold and myalgia. Hence treated with SYP.ASCORIL $10 \mathrm{ml}$ TDS, T.ACETAMNOPHEN 500mg SOS, T.MONTEC LC HS and T.DEFLAZACORT 6mg OD. The patient was provided creep bandage for the limb elevation. After 7 days of hospital stay, the patient was symptomatically improved and tested for rapid antigen test for covid 19 and found to be negative. Hence the patient was discharged without any issues.

\section{Case Report 3}

A 76 year old female patient was admitted with the complaints of mild breathlessness on and off. Patient is a known case of Intervertebral disc prolapsed (IVDP), asthma and on metered dose inhaler. She has a history of primary contact with her covid positive son and has no travel history. She was categorized into category A based on signs and symptoms. The test result of rapid antigen test for covid 19 was found to be positive. On examination, patient was afebrile, conscious and oriented, Her vitals showed: PR-76bpm, BP-160/90mmHg, RR-22bpm. All the lab parameters were normal except $D$-dimer was increased by 2 fold to $1085.54 \mathrm{ng} / \mathrm{ml}$. The patient was managed with T.ASCAZIN 50mg OD, T.VITAMIN C 500mg BD, T. CALDAY 1 TAB OD, T.FLUVIR 75mg BD for 5 DAYS,T.AZITHROMYCIN $500 \mathrm{mg}$ OD For 5 days. She was already on ready on BECLOMETHASONE+FORMETROL MDI 2 puffs. She was administered with INJ.ENOXAPARIN 40mg sc of for 3 days due to high levels of D-Dimer. During the course of treatment, patient had complaints of constipation, low back pain and was managed with SYP.LACTULOSE $10 \mathrm{ML}$ TDS SOS, T.ACETAMINOPHEN 500mg and DICLOFENAC GEL for local application. Following 7 days of hospital stay, the patient was symptomatically improved. Rapid Antigen test for covid 19 was tested on $8^{\text {th }}$ day and patient became negative and hence discharged.

\section{Case Report 4}

A 67 year old female patient was admitted for the complaints of fever, myalgia, loss of appetite and vomiting for past 4 days. He has a history of chest discomfort and the patient is a known case of Diabetes mellitus, Hypertension and CAD-IWMI,S/P PCl. Based on the signs and symptoms, patient was categorized into category $B$. The patient had no travel history but has a contact history with covid positive son. On examination, patient was febrile and conscious. Vitals of the patient include-BP$130 / 80 \mathrm{mmHg}$, PR-86bpm. Investigations revealed Hyponatremia with sodium level $118 \mathrm{mg} / \mathrm{dl}$, high glucose level with PPBS-315mg/dl and D-dimer-825.88ng/ml. Hyponatremia was corrected with T.TOLVAPTAN $15 \mathrm{mg}$ OD and INJ.ENOXAPRIN 40mg sc for high levels of D-Dimer. The patient was given T.ASCAZIN 1tab OD, T.VITAMIN C 500mg BD, T.MVT OD, T.PANTOPRAZOLE 40mg OD,T.AZITHROMYCIN 500mg OD,T.OSELTMIVIR 75mg BD for 5 days and INJ.ONDANSETRON 4MG TDS for 1 day. T.ASPIRIN 150mg OD, T.CLOPIDOGREL 75mg OD, T.ATORVASTATIN 40mg HS, T.METOPROLOL SUCCINATE 25 mg OD, T.ISOSORBIDE DINITRATE 10mg TDS, T.RAMIRIL $2.5 \mathrm{mg}$ OD and INJ.HUMAN MIXTARD SC. Patient had complaints of nausea on next day for which T.PANTOPRAZOLE $40 \mathrm{mg}$ was administered. The patient was screened on $10^{\text {th }}$ day and tested negative for rapid antigen test and was symptomatically improved, hence discharged.

\section{Case Report 5}

A 73 year old male patient was admitted for complaints of worsening of cough, poor appetite, shortness of breath and right sided chest pain for past 3 weeks. He was a known case of Hypertension, COPD, CAD and recent small cell carcinoma of lungs. He was screened for covid 19 by truenaat and was found to be positive. Based on signs and symptoms, the patient was categorized into Category $C$. The patient had no history of travel and has unknown exposure history. On general examination, patient was conscious, afebrile with Pulse rate-82bpm,BP$150 / 90 \mathrm{mmHg}, \mathrm{RR}-20 \mathrm{bpm}$. Investigations revealed HB$10.5 \mathrm{~g} / \mathrm{dl}, \mathrm{WBC}-11,600$ cells/cumm. The chest $\mathrm{x}$-ray shows massive pleural effusion. All LFT parameters were normal and D-dimer value as within limits. The patient was treated with T.PARACETAMOL+TRAMADOL TDS and T.GABAPENTIN 300mg BD for pain, T.ATORVASTATIN +CLOPIDOGREL 10mg HS for CAD, T.CILNIDIPINE 10mg BD for high BP, T.ACEBROPHYLLINE 100mg OD, SALMETROL+FLUTICASONE 2PUFF BD, INJ.CEFOPERZONE +SULBACTAM 1.5g IV BD for 5 days, T.FLUVIPIRAVIR $1800 \mathrm{mg}$ BD followed by $800 \mathrm{mg}$ BD for 5 days. The patient was administered INJ.ENOXAPARIN 40mg OD for high Ddimer level. Due to difficulty in breathing another bronchodilator INH.FORMETROL+BUDESONIDE 2puffs BD. The patient had complaints of gastric irritation, hence SYP.MUCAINE GEL $10 \mathrm{ML}$ TDS was added in addition to INJ.PANTOPRAZOLE 40mg OD. On 5th day, The SPO2 level of the patient was dropped to $80 \%$ and experienced breathlessness, hence provided immediate oxygen therapy at $2 \mathrm{~L} / \mathrm{min}$ and was shifted to ICU. The patient was on oxygen therapy at $3 \mathrm{~L} / \mathrm{min}$ in the next day too. She was symptomatically improved and was shifted to the ward. Following 14 days course in hospital, patient became 
asymptomatic and was screened for rapid antigen test and became negative. The patient had a good outcome and was discharged without any complications.

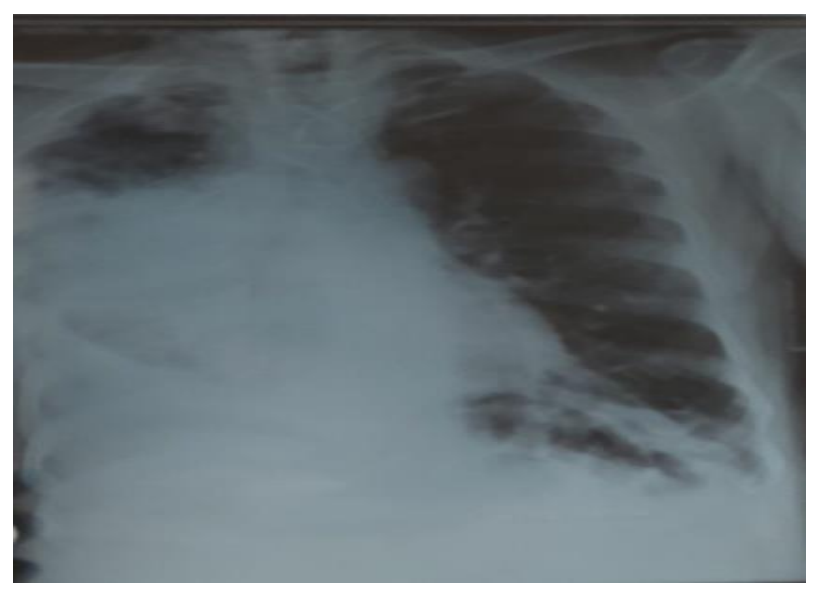

Chest X-Ray of the patient

\section{DISCUSSION}

COVID-19 is the source of severe viral pneumonia rapidly leading to ARDS. The clinical presentation of COVID-19 varies from asymptomatic or mild symptoms to clinical conditions characterized by respiratory failure that requires mechanical ventilation and oxygen support in an ICU, to multiorgan and systemic manifestations in terms of sepsis, septic shock, and multiple organ dysfunction syndromes (MODS). ${ }^{18}$ Based on the signs and symptoms, comorbidities as well as contact history, patients were classified into 3 categories as CATEGORY A,B and C. Out of 5 cases presented here, 1 case in each of category $A$ and $C$ and rest is classified into category $B$ group. All 5 patients were symptomatic as well as with multiple comorbidities and was discharged with good outcomes. In a case series of 135 patients, Wan et al reported $88.9 \%$ of patients presented with a fever and $76.5 \%$ had a cough. ${ }^{19}$ Fatigue and myalgias (32.5\%), headache (17.7\%), and dyspnea $(13.3 \%)$ were less commonly reported. ${ }^{19}$ Fever, cough, myalgia and breathlessness were symptoms present in our patients. There is no specific antiviral treatment recommended for COVID-19, and no vaccines are currently available. The treatment is based on symptoms, and oxygen therapy represents to be the first step for addressing respiratory impairment. Non-invasive (NIV) and invasive mechanical ventilation (IMV) may be necessary in cases of respiratory failure unmanageable to oxygen therapy. Two of our patients required oxygen therapy due to low level of SPO2 and breathing difficulty. Again, intensive care is needed to compact with complicated forms of the disease. In severe Covid 19 induced ARDS, DEXAMETHASONE has been found to be useful. Recent large-size Randomized controlled trial (the RECOVERY trial) demonstrated that DEXAMETHASONE $6 \mathrm{mg} / \mathrm{kg}$ for 10 days reduced deaths by one-third among critically ill COVID-19 patients. ${ }^{20}$ The patient presented with infection received treatment with VITAMIN C,CALCIUM and ZINC which helps to improve the immune system and helps in shortening the duration and improving outcomes in respiratory infections including pneumonia. ${ }^{21,22}$ All the positive patients of all 3 categories are given with theses vitamin supplement for developing immunity to fight infection. In addition to this, HYDROXYCHLOROQUINE and AZITHROMYCIN have obtained a large amount of attention for the managing COVID-19. HYDROXYCHLOROQUINE, a well-known antimalarial and auto-immune medication, is relatively cheap and has been broadly studied in the treatment for COVID-19. ${ }^{1}$ CHLOROQUINE $(500 \mathrm{mg}$ for every 12 hours), and HYDROXYCHLOROQUINE (200 mg every 12 hours) were proposed for immunomodulatory therapy. In a non-randomized trial, Gautret et al., ${ }^{24}$ showed that HYDROXYCHLOROQUINE was significantly associated with viral load reduction until viral disappearance and this effect was enhanced by the MACROLIDES AZITHROMYCIN. In vitro and in vivo studies, indeed, have shown that MACROLIDES may alleviate inflammation and modulate the immune system. In our cases, HYDROXYCHLOROQUINE and AZITHROMYCIN were mostly used in combination with either FLUVIR or FLUVIPIRAVIR in Category B patients. Also in addition to supplements, AZITHROMYCIN 500mg OD has also been widely used in category $A$ patients. Other treatments for COVID-19 have also emerged and have so far shown promising results in ongoing clinical trials. Of these, REMDESIVIR (GS-5734) AND FAVIPIRAVIR (T-705) have become the center of attention. ${ }^{24}$ FAVIPIRAVIR, an RNA-dependent RNA polymerase inhibitor, has already obtained approval for the treatment of COVID-19 in China on February 15th, 2020. ${ }^{25}$ Studies have shown FAVIPIRAVIR inhibited RNA polymerase activity and thus prevented replication of RNA viruses like COVID-19 with minimal side effects. ${ }^{25}$ FAVIPIRAVIR in combination with AZITHROMYCIN has shown better and more rapid response in complicated cases. Further studies and clinical trials are required to fully understand the role of REMDESIVIR in COVID-19 infected patients. ${ }^{1}$ Several anti-flu drugs such as OSELTAMIVIR have been used for the treatment of COVID-19 patients. ${ }^{16}$ In our cases, FLUVIR has been prescribed in combination with AZITHROMYCIN and other supplements and not alone. Because COVID-19 patients have a better incidence of venous thromboembolism and anticoagulant therapy is related to reduced ICU mortality, it is suggested that patients should receive thromboprophylaxis. Moreover, in the case of known thrombophilia or thrombosis, full therapeutic-intensity anticoagulation (e.g., ENOXAPARIN 1 $\mathrm{mg} / \mathrm{kg}$ twice daily) is indicated. ${ }^{26}$ In our patients with high d-dimer values, patients were administered INJ.ENOXAPARIN 40mg for 1 to 3 days depending on dimer values.

\section{CONCLUSION}

COVID-19 is a serious infection that can lead to severe pneumonia, ARDS, and even high mortality rate across the globe. Until today there are no approved treatments for this viral pandemic. While several medications have shown to be effective in clinical trials, further studies are needed to establish dosing, treatment course, and side effects of these medications. Although the lack of rapid testing for COVID-19 has caused a delay in diagnosis, the use of CT 
scans could provide an increased suspicion of COVID-19 infection leading to earlier treatment and management. The alarming rise in number of cases and deaths continue to increase in the world, the race to develop faster testing modalities to rapidly diagnose and manage these patients earlier continues to be the focus of the global healthcare system.

\section{REFERENCES}

1. Douedi S, Miskoff J. Novel coronavirus 2019 (COVID19): A case report and review of treatments. Medicine. 99(19), 2020 May 1, e20207.

2. https://www.who.int/emergencies/diseases/novelcoronavirus-2019

3. Krishnakumar B, Rana S. COVID 19 in INDIA: Strategies to combat from combination threat of life and livelihood. Journal of Microbiology, Immunology and Infection. 2020 Mar 28.

4. Kumar SU, Kumar DT, Christopher BP, Doss C. The Rise and Impact of COVID-19 in India. Frontiers in Medicine. 7, 2020 May 22, 250.

5. CDC. 2019 Novel Coronavirus, Wuhan, China: Symptoms. CDC. Available at https://www.cdc.gov/coronavirus/2019ncov/about/symptoms.html. January 26, 2020; Accessed: January 27, 2020.

6. Lauer $\mathrm{SA}$, Grantz $\mathrm{KH}, \mathrm{Bi} \mathrm{Q}$, Jones FK, Zheng $\mathrm{Q}$, Meredith HR, Azman AS, Reich NG, Lessler J. The incubation period of coronavirus disease 2019 (COVID-19) from publicly reported confirmed cases: estimation and application. Annals of internal medicine. 172(9), 2020 May 5, 577-82.

7. Luers JC, Rokohl AC, Loreck N, Wawer Matos PA, Augustin $M$, Dewald F, Klein F, Lehmann C, Heindl LM. Olfactory and gustatory dysfunction in Coronavirus disease 19 (COVID-19). Clinical Infectious Diseases. 2020 May 1.

8. Guan WJ, Ni ZY, Hu Y, Liang WH, Ou CQ, He JX, Liu L, Shan $\mathrm{H}$, Lei CL, Hui DS, Du B. Clinical characteristics of coronavirus disease 2019 in China. New England journal of medicine. 382(18), 2020 Apr 30, 1708-20.

9. Chen N, Zhou M, Dong X, Qu J, Gong F, Han Y, Qiu Y, Wang J, Liu Y, Wei Y, Yu T. Epidemiological and clinical characteristics of 99 cases of 2019 novel coronavirus pneumonia in Wuhan, China: a descriptive study. The Lancet. 395(10223), 2020 Feb 15, 507-13.

10. Cheung KS, Hung IF, Chan PP, Lung KC, Tso E, Liu R, Ng YY, Chu MY, Chung TW, Tam AR, Yip CC. Gastrointestinal manifestations of SARS-CoV-2 infection and virus load in fecal samples from the Hong Kong cohort and systematic review and metaanalysis. Gastroenterology. 2020 Apr 3.
11. CDC. 2019 Novel Coronavirus, Wuhan, China: Frequently Asked Questions and Answers. CDC. January 27, 2020; Accessed: January 27, 2020.

12. Centers for Disease Control and Prevention. Coronavirus Disease 2019: COVID-19.

13. Steenhuysen J. U.S. health officials seek emergency approval to use diagnostic test for new coronavirus. Reuters. January 23, 2020; Accessed: January 27, 2020.

14. Quick and affordable saliva-based COVID-19 test developed by Yale scientists receives FDA Emergency Use Authorization. YaleNews. 2020 Aug 15.

15. Hui DS, Azhar El, Madani TA, Ntoumi F, Kock R, Dar O, Ippolito G, Mchugh TD, Memish ZA, Drosten C, Zumla A. The continuing 2019-nCoV epidemic threat of novel coronaviruses to global health-The latest 2019 novel coronavirus outbreak in Wuhan, China. International Journal of Infectious Diseases. 91, 2020 Feb 1, 264-6.

16. Chen N, Zhou M, Dong X, Qu J, Gong F, Han Y, Qiu Y, Wang J, Liu Y, Wei Y, Yu T. Epidemiological and clinical characteristics of 99 cases of 2019 novel coronavirus pneumonia in Wuhan, China: a descriptive study. The Lancet. 395(10223), 2020 Feb 15, 507-13.

17. Roschewski M, Lionakis MS, Sharman JP, Roswarski J, Goy A, Monticelli MA, Roshon M, Wrzesinski SH, Desai JV, Zarakas MA, Collen J, Rose K, Hamdy A, Izumi R, Wright GW, Chung KK, Baselga J, Staudt LM, Wilson WH. Inhibition of Bruton tyrosine kinase in patients with severe COVID-19. Sci Immunol. 5(48), 2020 Jun 05.

18. Cascella M, Rajnik M, Cuomo A, Dulebohn SC, Di Napoli R. Features, evaluation and treatment coronavirus (COVID-19). InStatpearls [internet] 2020 Mar 8. StatPearls Publishing.

19. Wan S, Xiang $Y$, Fang $W$, et al. Clinical features and treatment of COVID-19 patients in northeast Chongqing. J Med Virol 2020, 1-10. DOI:10.1002/jmv.25783.

20. Ledford $\mathrm{H}$. Coronavirus breakthrough: dexamethasone is first drug shown to save lives. Nature. 582(7813), 2020 Jun 1, 469.

21. Carr AC, Maggini S. Vitamin $C$ and immune function. Nutrients. 9(11), 2017 Nov, 1211.

22. Wintergerst ES, Maggini S, Hornig DH. Immuneenhancing role of vitamin $\mathrm{C}$ and zinc and effect on clinical Conditions. Ann Nutr Metab 50, 2006, 85-94.

23. Gautret $P$, Lagier JC, Parola $P$, Meddeb L, Mailhe $M$, Doudier B, Courjon J, Giordanengo V, Vieira VE, Dupont HT, Honoré S. Hydroxychloroquine and azithromycin as a treatment of COVID-19: results of an open-label non-randomized clinical trial. 
International journal of antimicrobial agents. 2020 Mar 20:105949.

24. Wang $M$, Cao R, Zhang L, Yang X, Liu J, Xu M, Shi Z, Hu Z, Zhong W, Xiao G. Remdesivir and chloroquine effectively inhibit the recently emerged novel coronavirus (2019-nCoV) in vitro. Cell research. 30(3), 2020 Mar, 269-71.

25. Dong L, Hu S, Gao J. Discovering drugs to treat coronavirus disease 2019 (COVID-19). Drug discoveries \& therapeutics. 14(1), 2020 Feb 29, 5860 .

26. Kollias A, Kyriakoulis KG, Dimakakos E, Poulakou G, Stergiou GS, Syrigos K. Thromboembolic risk and anticoagulant therapy in COVID-19 patients: emerging evidence and call for action. British journal of haematology. 189(5), 2020 Jun, 846-7.

Source of Support: None declared.

For any question relates to this article, please reach us at: editor@globalresearchonline.net

New manuscripts for publication can be submitted at: submit@globalresearchonline.net and submit_ijpsrr@rediffmail.com 